\title{
Analisis Kualitas Jaringan Internet Pada Pulau Rempang Galang Kota Batam
}

\author{
Yuli Siyamto ${ }^{1 *}$, Asron Saputra ${ }^{2 * *}$ \\ * Sistem Informasi, Universitas Putera Batam \\ ** Manajemen, Universitas Putera Batam \\ ysiyamto46@gmail.com ${ }^{1}$, asron.2805@gmail.com ${ }^{2}$
}

\begin{tabular}{l}
\hline Article Info \\
\hline Article history: \\
Received 2019-10-11 \\
Revised 2019-10-29 \\
Accepted 2019-11-01 \\
\hline
\end{tabular}

Keyword:

Network, Analyst,

Internet, QoS.

\begin{abstract}
This study aims to determine the extent of the quality of cellular-based internet network services in the coastal areas of Batam, especially on Rempang Galang Island. The background of the research is to increase public awareness to use the internet for economic development and to improve the quality of human resources. With the internet, the people of Rempang Galang Island can open their insights, knowledge, skills, market share and wider business opportunities. This awareness has also led to an increase in the number of people who use cellular-based internet. With cellularbased, many advantages are obtained. Among others, it does not depend entirely on PLN electricity, mobility and flexibility and has many uses. In order to serve the needs of the Rempang Galang community for good internet network services, a study is needed to find out the facts on the ground. The research method used is the QoS (Quality Of Service) method. The main parameters of throughput, delay, packet loss, and jitter with reference standards are TIPHON (Telecommunications and Internet Protocol Harmonization over Networks). The tools used are Axis NetTools, Wireshark and Iperf. The results of the study will obtain a picture of the quality of cellular-based internet network services on Rempang Galang Island, Batam City. The final goal of the research is as input for the Batam City Government and the private sector in order to jointly build the Batam City to be more advanced and equitable.
\end{abstract}

\section{Pendahuluan}

Dewasa ini kebutuhan layanan internet telah berubah menjadi kebutuhan primer bagi individu maupun organisasi. Jaringan komputer adalah dua atau lebih komputer yang terhubung dan dapat membagi data, aplikasi, peralatan komputer, dan koneksi internet atau beberapa kombinasi itu [1]. Jaringan komputer dapat diartikan sebagai suatu himpunan interkoneksi sejumlah komputer otonom. Dua buah komputer dikatakan membentuk suatu network bila keduanya dapat saling bertukar informasi [2]. Jaringan komputer merupakan kumpulan komputer, printer dan peralatan lainnya yang terhubung antara satu dengan yang lain. Dua buah komputer dikatakan terhubung bila keduanya dapat saling bertukar data dan informasi [3]. Layanan komunikasi data melalui jaringan seluler menjadikan komunikasi tanpa batas (seamless communication) terus dikembangkan dari teknologi EDGE, GPRS, 3G, HSDPA hingga 4G sekarang ini. Layanan atau pelayanan adalah pemberian jasa baik oleh pemerintah, pihak swasta atas nama pemerintah ataupun pihak swasta kepada masyarakat, dengan atau tanpa pembayaran guna memenuhi kebutuhan dan kepentingan masyarakat [4][5]. Melalui internet, berbagai macam informasi dapat diperoleh secara mudah dan cepat. Berbagai informasi tersebut dapat diolah dengan tepat untuk menambah wawasan pengetahuan dan peluang usaha.

Kota Batam adalah sebuah kota terbesar di Provinsi Kepulauan Riau. Wilayah Kota Batam terdiri dari pulau Batam, pulau Rempang dan pulau Galang dan pulau-pulau kecil lainnya di kawasan Selat Singapura dan Selat Malaka. Sebagai kota terencana, Batam merupakan salah satu kota dengan pertumbuhan terpesat di Indonesia. Namun pembangunan yang dilakukan oleh Pemerintah Kota Batam masih belum merata, terutama bagi pulau-pulau pesisir. Hal ini menyebabkan masyarakat pesisir (Rempang Galang) tertinggal dalam berbagai segi seperti kualitas sumber daya 
manusia dan perekonomian. Perbedaan kualitas sumber daya manusia dapat dilihat secara nyata di dunia kerja. Perusahaanperusahaan Batam mayoritas menerima tenaga kerja yang merupakan lulusan sekolah perkotaan. Bahkan perusahaan banyak yang merekrut karyawan dari pulau Jawa. Perusahaan menganggap lulusan dari sekolah pulau pesisir Batam, tidak memiliki pengetahuan, ketrampilan dan kualitas untuk baik di dunia kerja.

Di bidang ekonomi, pembangunan infrastruktur dan pertumbuhan ekonomi lebih banyak dinikmati oleh penduduk yang tinggal di daerah perkotaan daripada penduduk yang tinggal di wilayah pesisir seperti Rempang dan Galang, sehingga cenderung terjadi kesenjangan ekonomi antara penduduk di daerah perkotaan dengan penduduk di daerah pesisir. Pengembangan kawasan industri Batam salah satunya mengakibatkan penduduk setempat termarginalkan. Penduduk setempat Kota Batam adalah orang Melayu yang biasa disebut orang tempatan, yang tinggal di daerah-daerah pesisir (hinterland) Kota Batam. Penduduk di daerah pesisir pada umumnya adalah nelayan [6] yang masih hidup dalam kemiskinan. Mereka pada umumnya hidup dari menangkap ikan di laut dan mencari kayu bakau (mangrove) untuk dijadikan arang kayu [7].

Melalui berbagai informasi dari beberapa media televisi maupun kegiatan-kegiatan kampus di Batam, maka banyak masyarakat pesisir khususnya Rempang Galang dapat mengenal dan mengerti akan kegunaan dari internet. Melalui internet, masyarakat mendapatkan banyak wawasan dan ketrampilan untuk membuka jenis-jenis usaha ekonomi yang lebih variatif. Masyarakat juga dapat mengembangan usaha atau memperluas pangsa pasarnya. Bagi para pelajar di Rempang Galang, keberadaan internet dapat dijadikan tempat belajar dan mencari referensi pengetahuan untuk menambah kualitasnya. Dengan besarnya manfaat internet ini menyebabkan peningkatan jumlah pengguna layanan internet pada masyarakat pesisir pulau Rempang Galang. Adalah jenis layanan berbasis seluler yang mengalami peningkatan sangat signifikan. Hal ini karena harga handphone android bekas yang murah serta kondisi pelayanan listrik daerah pesisir masih terbatas. Keunggulan handphone adalah tidak tergantung sepenuhnya pada listrik PLN, hemat listrik, memiliki mobilitas dan fleksibelitas yang tinggi. Para provider di Batam menyediakan kartu internet yang murah.

Untuk memenuhi kebutuhan masyarakat ini, maka diperlukan gambaran yang akurat dan real tentang kualitas layanan jaringan internet daerah pesisir utamanya daerah Rempang Galang. Sehingga rencana pembangunan pemerintah menjadi tepat sasaran, adil dan merata. Untuk penelitian ini, maka pembahasan dibatasi beberapa hal. Yaitu objek yang di teliti adalah daerah Rempang Galang berupa kawasan sekolah menegah atas, pusat pembelanjaan, pasar. Hasil penelitian ini juga tidak akan dijadikan sebuah strategi utama pihak yang diteliti, namun hanya sebatas rekomendasi atau saran.

Untuk memperkuat pustaka dalam penelitian, maka perlu dipaparkan beberapa penelitian yang sudah terbit sebelumnya. Pertama penelitian yang berjudul Analisis Kualitas Layanan Jaringan WLAN dengan Metode QoS pada Taman Internet Kota Batam [8]. Hasil akhir penelitian ini diperoleh gambaran kualitas jaringan internet pada Taman Internet Kota Batam berada di level 3 (Good). Artinya kualitas jaringan WLAN sudah baik dan sesuai kepentingan dan kebutuhan masyarakat Kota Batam pengguna layanan. Penelitian yang kedua berjudul Peningkatan Kesejahteraan Masyarakat Pesisir di Kota Batam melalui Pemberdayaan Masyarakat [9]. Didapatkan temuan bahwa Batam sebagai kawasan perdagangan bebas, tidak terlepas dari permasalahan kemiskinan. Pertumbuhan ekonomi yang tinggi di Batam pada kenyataannya telah memarginalkan masyarakat setempat, yang lebih banyak tinggal di daerah-daerah pesisir (hinterland) Kota Batam. Mereka adalah masyarakat nelayan yang jarang mendapatkan sentuhan program pembangunan [5]. Sebagian besar mereka hidup dalam kemiskinan, yang memiliki keterbatasan tidak hanya dari ketidakmampuan mereka untuk memenuhi kebutuhan dasar tetapi juga keterbatasan atas sarana prasana kehidupan mereka.

\section{Metode Penelitian}

Desain penelitian merupakan tahap-tahap dasar dalam melakukan sebuah penelitian ilmiah. Adapun desain penelitian pada penelitian ini dapat dilihat pada gambar 1 dibawah ini.

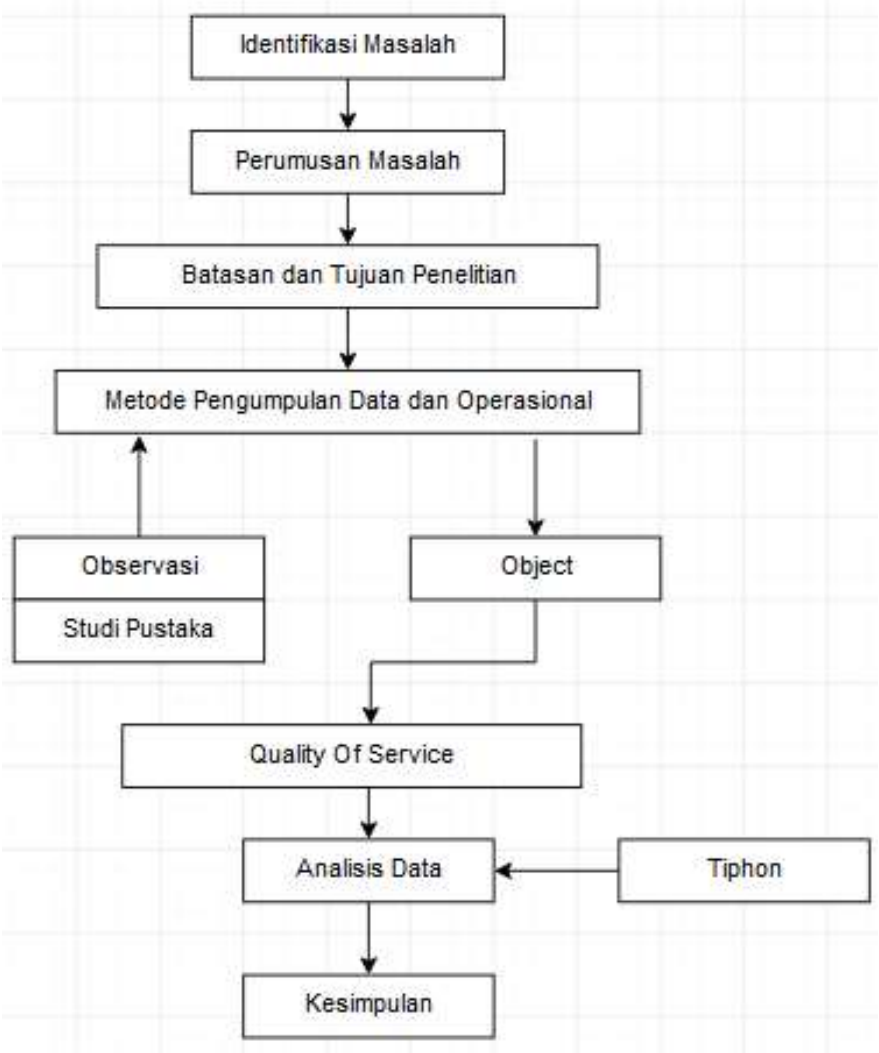

Gambar 1. Desain Penelitian

Metode penelitian yang digunakan dalam penelitian ini menggunakan metode tindakan (action research) yang terdiri dari beberapa tahapan. 


\section{1) Diagnosing}

Pertama melakukan identifikasi masalah pokok yang ada guna menjadi dasar melakukan penelitian.

\section{2) Action Planning}

Action planning melakukan studi pustaka yaitu mencari referensi, metode dan algoritma untuk solusi dari permasalahan.Kedua, menetapkan metode pengumpulan dan pengukuran atau analisis data. Metode QoS (Quality of Service) adalah kemampuan suatu jaringan untuk menyediakan layanan yang baik dengan menyediakan bandwith, mengatasi jitter dan delay. Parameter QoS adalah latency, jitter, packet loss, throughput, MOS, echo cancellation dan PDD. QoS sangat ditentukan oleh kualitas jaringan yang digunakan. Terdapat beberapa faktor yang dapat menurunkan nilai QoS, seperti: redaman, distorsi, dan noise [10]. Quality of Service (QoS) merupakan metode pengukuran tentang seberapa baik jaringan dan merupakan suatu usaha untuk mendefinisikan karakteristik dan sifat dari satu servis. QoS digunakan untuk mengukur sekumpulan atribut kinerja yang telah dispesifikasikan dan diasosiasikan dengan suatu servis [11]. Beberapa parameter quality of service yang dipergunakan yaitu throughput, delay, packet loss, dan jitter [12]. Ketiga, merencanakan pengukuran di daerah Rempang Galang.

\section{3) Action Taking}

Melakukan pengambilan data untuk setiap obyek-obyek penelitian. Pengukuran nilai throughput memanfaatkan software Axence Nettools. Pengukuran delay dan packet loss menggunakan aplikasi perangkat lunak Wireshark, pengukuran jitter menggunakan aplikasi perangkat lunak iperf. Pengukuran dilakukan pada 3 kartu internet berbeda yaitu Simpati, IM3, Three.

\section{4) Melakukan evaluasi (Evaluating)}

Melakukan evaluasi dan analisis terhadap hasil pengukuran yang didapatkan dengan membandingkan dengan standart TIPHON [13]. Untuk tabel kualitas QOS sesuai standar TIPHON dapat dilihat pada tabel 1 berikut.

TABEL I

INDEKS QOS VERSI TIPHON

\begin{tabular}{|c|c|c|}
\hline Nilai & Persentase (\%) & Index \\
\hline $3,8-4$ & $95-100$ & $\begin{array}{c}\text { Sangat } \\
\text { bagus }\end{array}$ \\
\hline $\begin{array}{c}3- \\
3,79\end{array}$ & $75-95,75$ & Bagus \\
\hline $\begin{array}{c}2- \\
2,99\end{array}$ & $50-74,75$ & Sedang \\
\hline $\begin{array}{c}1- \\
1,99\end{array}$ & $25-49,75$ & Jelek \\
\hline
\end{tabular}

\section{5) Learning}

Data hasil analisis dipelajari dan didalami untuk mendapatkan sebuah kesimpulan.

\section{HASIL DAN PEMBAHASAN}

Berdasarkan dari pengukuran QoS, didapatkan hasil pengukuran nilai througput, delay dan packet loss serta jitter, dimana proses pengukurannya menggunakan software Axence NetTools, Wireshark dan Iperf.

TABEL II

REKAPITUlasi Hasil PENGUKURAN

\begin{tabular}{|c|c|c|c|c|c|}
\hline Lokasi & Kartu & $\begin{array}{c}\text { Throu } \\
\text { gput } \\
\%\end{array}$ & $\begin{array}{c}\text { Packet } \\
\text { Loss } \\
\%\end{array}$ & $\begin{array}{c}\text { Delay } \\
\mathbf{m} / \mathbf{s}\end{array}$ & $\begin{array}{c}\text { Jitter } \\
\mathbf{m} / \mathbf{s}\end{array}$ \\
\hline \multirow{3}{*}{ SMA N 10} & $\mathrm{~S}$ & 66,35 & 0 & 12,2 & 0,004 \\
\hline & I & & & & \\
\hline & $\mathrm{T}$ & & & & \\
\hline \multirow{3}{*}{$\begin{array}{l}\text { Nano Mart } \\
\text { Galang }\end{array}$} & $\mathrm{S}$ & 73,14 & 0,4 & 11,98 & 0,013 \\
\hline & I & 69,48 & 0 & 13,01 & 0,004 \\
\hline & $\mathrm{T}$ & & & & \\
\hline \multirow{3}{*}{ SMA N 9} & $\mathrm{~S}$ & 70,55 & 0,1 & 30,32 & 0,024 \\
\hline & I & & & & \\
\hline & $\mathrm{T}$ & & & & \\
\hline \multirow{3}{*}{$\begin{array}{c}\text { Botanical } \\
\text { Garden Batam }\end{array}$} & $\mathrm{S}$ & 72,16 & 0 & 105,77 & 0,049 \\
\hline & I & 57,53 & 0,2 & 14,21 & 0,112 \\
\hline & $\mathrm{T}$ & & & & \\
\hline \multirow{3}{*}{$\begin{array}{l}\text { Pasar Teri } \\
\text { Galang }\end{array}$} & $\mathrm{S}$ & 76,89 & 2 & 132,79 & 0,051 \\
\hline & I & & & & \\
\hline & $\mathrm{T}$ & & & & \\
\hline \multirow{3}{*}{$\begin{array}{l}\text { Puskesmas } \\
\text { Rempang }\end{array}$} & $\mathrm{S}$ & 70,43 & 0 & 10,75 & 0,013 \\
\hline & I & 68,8 & 0 & 9,33 & 0,002 \\
\hline & $\mathrm{T}$ & & & & \\
\hline \multirow{3}{*}{ Jembatan 2} & $\mathrm{~S}$ & 63,73 & 0 & 14,31 & 0,58 \\
\hline & I & 40,73 & 0 & 11,64 & 0,003 \\
\hline & $\mathrm{T}$ & 47,76 & 0,4 & 54,15 & 0,055 \\
\hline \multirow{3}{*}{ Jembatan 1} & $\mathrm{~S}$ & 75,85 & 0 & 3,78 & 0,003 \\
\hline & I & 72,32 & 0 & 4,98 & 0 \\
\hline & $\mathrm{T}$ & 69,22 & 0 & 1,67 & 0,052 \\
\hline
\end{tabular}

Tabel 2 menunjukkan hasil rekapitulasi pengukuran diatas, jika dirata-rata nilai throughput sebesar 66,63\%. Artinya throughput berada pada index 3 dan kategori bagus. Nilai rata-rata packet loss sebesar 0,207 \% atau tidak melebihi $3 \%$. Artinya packet loss berada pada index 4 dan kategori sangat bagus. Nilai rata-rata delay jika dikalkulasikan sebesar 28,7 ms. Artinya delay berada pada index 4 dan kategori sangat bagus. Nilai rata-rata jitter jika dikalkulasikan sebesar 0,064 ms. Artinya jitter berada pada index 4 dan kategori sangat bagus. Dari hasil perhitungan rata-rata nilai througput, delay dan packet loss serta jitter maka didapatkan nilai QoS 3,75 bps. Jika dibandingkan dengan standar TIPHON, artinya 
kualitas jaringan internet di Rempang Galang dalam kategori bagus.

Tabel 2 juga menunjukkan bahwa ada beberapa titik di pulau Galang, dimana jaringan internet nya tidak terdeteksi. Sedangkan di Pulau Galang Baru, hanya 1 provider yang terdeteksi. Berdasarkan pengamatan langsung pada saat proses pengambilan data, jumlah tower BTS di daerah Rempang Galang memang cukup terbatas. Lokasi tower hanya berada di sepanjang Jalan Trans Barelang. Sedangkan struktur tanah di Rempang Galang berbukit-bukit. Hasil ini relevan dengan data dari nperf.com bahwa tidak semua sinyal provider Indonesia terdeteksi di Pulau Rempang Galang [14].

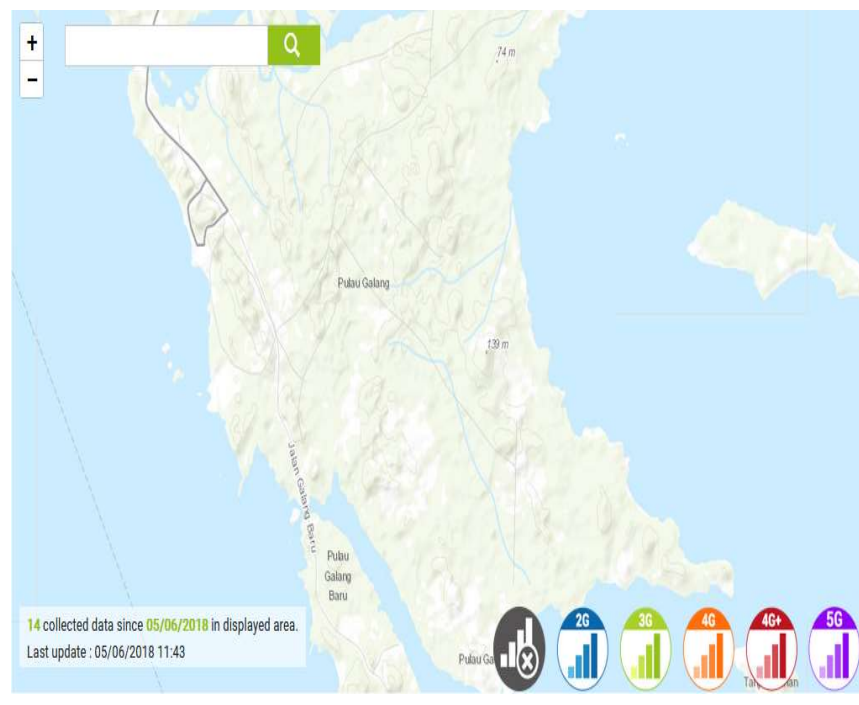

Gambar 2. Data Coverage Map Provider T

\section{KESIMPULAN}

Berdasarkan hasil penelitian, dapat disimpulkan bahwa hasil pengukuran Quality of Service jaringan internet di Rempang Galang Kota Batam menunjukkan kategori bagus. Sehingga pada garis besarnya, jaringan internet Rempang Galang Kota Batam sudah baik dan mampu melayani kebutuhan masyarakat. Namun belum semua provider memberikan layanan internet yang menjangkau untuk masyarakat di Pulau Galang.

\section{UCAPAN TERIMA KASIH}

Penulis mengucapkan terima kasih kepada Direktorat Riset dan Pengabdian kepada Masyarakat (DRPM) atas pendanaan Penelitian Dosen Pemula tahun 2018 yang telah diberikan.

\section{DAFTAR PUSTAKA}

[1] N. Zendrato, "Analisis Pemanfaatan Bandwith Pada Off-Time Kantor Menggunakan Mikrotik Dan Radius Server," Sinkron, vol. 1, no. 1, pp. 25-29, 2016

[2] A. Kadir and K. Tone, "Analisa Kerja Access Point Jaringan Wireles Pada Universitas Al Asyariah Mandar,” J. Ilmu Komput. FiKom Unasman, vol. 1, no. 1, pp. 4-7, 2015.

[3] P. Silitonga and I. S. Morina, "Analisis QoS (Quality of Service) Jaringan Kampus dengan Menggunakan Microtic Routerboard (Studi Kasus: Fakultas Ilmu Komputer Unika Santo Thomas S.U)," TIMES, vol. III, no. 2, pp. 19-24, 2014

[4] Abdullah and A. Rahman Majid, "Penguatan pelayanan pemerintah kabupaten studi efektivitas program sms center pada 3 tahun terakhir di Kabupaten Ponorogo," Komuniti, vol. VIII, no. September, 2016.

[5] D. E. Kurniawan, and A. Fatulloh, 'Clustering of Social Conditions in Batam, Indonesia Using K-Means Algorithm and Geographic Information System', Int. J. Earth Sci. Eng., vol. 10, no. 05, pp. 1076-1080, 2017.

[6] D. E. Kurniawan, N. Z. Janah, A. Wibowo, M. K. Mufida, and P. Prasetyawan, 'C2C marketplace model in fishery product trading application using SMS gateway', MATEC Web Conf., vol. 197, 2018.

[7] Widyatun, "One Decade of Human Resources Development In The Coastal Areas : Achievements And Challenges ( Case Of Mapur Island, Bintan Regency )," vol. 11, no. 2, pp. 119-132, 2016.

[8] Y. Siyamto, "Analisis Kualitas Layanan Jaringan WLAN Dengan Metode QoS Pada Taman Internet Kota Batam," J. Tek. Ibnu Sina, vol. 3, no. 2, pp. 83-88, 2018.

[9] S. N. Qodriyatun, "Peningkatan Kesejahteraan Masyarakat Pesisir di Kota Batam Melalui Pemberdayaan Masyarakat," Aspirasi, 2013.

[10] A. Setiawan, A. Handojo, and R. Hadi, "Indonesian Culture Learning Application based on Android," vol. 7, no. 1, pp. 526535, 2017.

[11] R. Wulandari, "Analisis QoS ( Quality of Service ) Pada Jaringan Internet ( Studi Kasus: UPT Loka Uji Teknik Penambangan Jampang Kulon - LIPI )," vol. 2, no. 2, pp. 162-172, 2016.

[12] I. Iskandar and A. Hidayat, "Analisa Quality of Service ( QoS ) Jaringan Internet Kampus ( Studi Kasus : UIN Suska Riau )," J. CoreIT, vol. 1, no. 2, pp. 67-76, 2015.

[13] Y. A. Pranata, I. Fibriani, and S. B. Utomo, "Analisis Optimasi Kinerja Quality of Service Pada Layanan Komunikasi Data Menggunakan NS - 2 di PT . PLN ( Persero ) Jember," vol. 20, no. 1 , pp. 149-156, 2015.

[14] " $3 \mathrm{G} / 4 \mathrm{G} / 5 \mathrm{G}$ coverage map, Indonesia." [Online]. Available: https://www.nperf.com/en/map. 